\title{
O lobisomem entre índios e brancos: o trabalho da imaginação no Grão-Pará no final do século XVIII ${ }^{1}$
}

\author{
Mark Harris $^{2}$
}

\section{Resumo}

Trata-se de uma investigação sobre imagens do lobisomem em Portugal e sua mescla com várias entidades transformativas da Amazônia no fim do século XVIII no Grão-Pará. A análise é baseada em documentos existentes no Arquivo Público do Estado do Pará, em Belém. Nesse sentido, este artigo é mais metodológico e teórico - como fazer um estudo do "pensamento mestiço" (de Serge Gruzinski) usando documentação judiciária - do que etnográfico. Tal como Gruzinski, considero que as atividades de criar analogias imperfeitas têm um valor de redenção, de salvar as pessoas da esterilidade e da destruição da conquista. Em outras palavras, o esboço que Gruzinski nos oferece representa a possibilidade de ver as inovações populares no tempo colonial e imperial como pontes da imaginação, ligando as diferenças e hierarquias formais com as práticas e relações cotidianas. Meu esforço se direciona também a examinar o significado da mestiçagem para pessoas que estavam realizando o trabalho de conexão e construção de novos e complexos compostos. Meu objetivo é contribuir para uma revisão da historiografia sobre a Amazônia, da qual participam historiadores e antropólogos no Brasil, onde ou se destacam o sofrimento e o holocausto da época colonial, ou se faz uma narrativa da emergência do povo paraense ou amazonense associada à condição de elite regional e ao Estado. Uma nova historiografia tenta reconhecer outras histórias, assim como a complexidade e a heterogeneidade da região.

\section{Palavras-chave}

Amazônia, mestiçagem, imaginação, Ameríndios, historiografia, lendas, mitos.

1 Apresentação realizada no Instituto de Estudos Brasileiros da Universidade de São Paulo, em 28 de fevereiro de 2008. Agradeço o convite da Profa Dra Marta Amoroso.

2 Professor do Departamento de Antropologia Social Social da Universidade de St. Andrews (St. Andrews, Escócia).

E-mail:mh25@st-andrews.ac.uk 


\title{
The werewolf in between indians and whites: \\ the work of the imagination in Grão-Pará at the end of the eighteenth century
}

\author{
Mark Harris
}

\begin{abstract}
The understanding of the Amazon's colonial period as the secure imposition of Portuguese control on powerless and scattered Indian peoples is misleading. The representation obscures Indian acts of resistance, the efforts of thousands of colonists to adapt and the emergence of a mestiço population, as well as the local negotiations between these heterogeneous groups. Little research has been conducted on the popular culture or religion in the Amazon during this time despite the existence of various sources. Developing arguments made elsewhere in Brazil, and using documents from the State archive of Pará, Brazil, this article reveals something of the popular culture which appeared as the diverse traditions converged. It was a way of life impregnated with complex negotiations and tense congregations of beliefs and practices that would eventually lead to a region wide, mass participation rebellion in the 1830s. The focus of the text is a legal action brought by a Brazilian born town official in 1793 accused of being werewolf and scaring Indians and whites in the Lower Amazon. What was the significance of the werewolf and what work was the figure doing locally? By reconstructing aspects of this colonial world, my argument is that the Portuguese derived figure of the werewolf acted as a bridging concept to similar transformative beings in the Amerindian world. I suggest the bridges made by the diverse kinds of people represent an imaginative frontier and was the localised form in which whites, mestiços and Indians came to relate each other.
\end{abstract}

Keywords

Amazonia, hybridity, imagination, Amerindians, historiography, folktales, myths. 


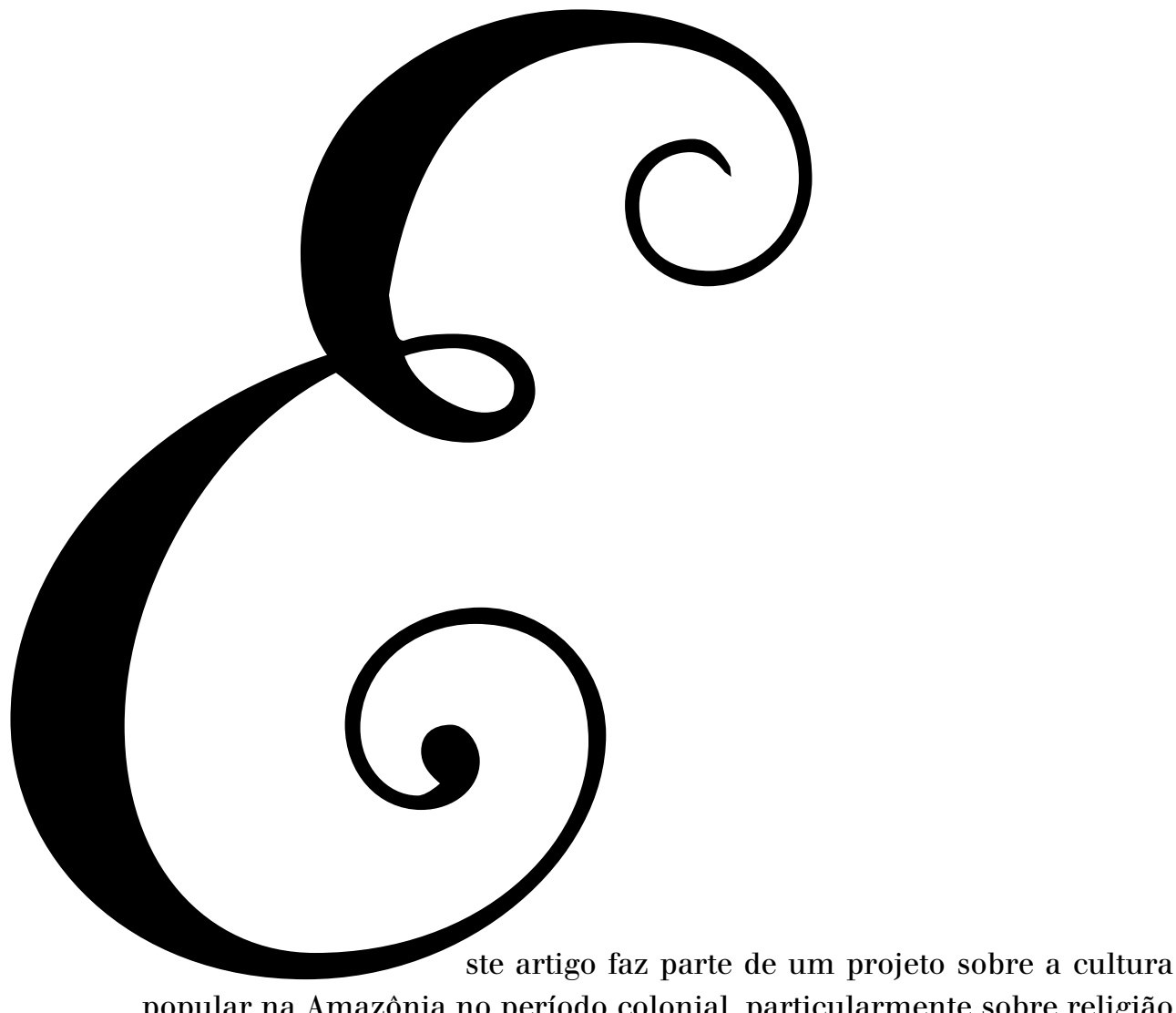
popular na Amazônia no período colonial, particularmente sobre religião popular. $\mathrm{O}$ que me interessa é a rede de comunicação desenvolvida entre os vários grupos e indivíduos, como o uso de símbolos, práticas e rituais. Essas comunicações articularam um espaço em comum. "Em comum" não significa que havia os mesmos interesses ou entendimentos: é "a zona de contato", de Mary Louise Pratt ${ }^{3}$, o espaço colonial onde as culturas se encontram e conflitam. Pode ser também o "terreno do meio", de Richard White $^{4}$, que estudou as interações entre índios e europeus na região dos Grandes Lagos na América do Norte. Ao longo do tempo, emergem várias conexões e mediações, o que pode levar a um entendimento transcultural ou a um desentendimento. Refiro-me às línguas populares, com termos e categorias locais e específicos, festas, parentesco, religião, trabalho, contos, tudo o que se passa no espaço público e da comunicação. Podemos ver isso como a arte do possível, um mundo cheio de acomodações e transigências entre os diversos interesses.

3 Cf. PRATT, Mary Louise. Imperial eyes: travel writing and transculturation. New York: Routledge, 1992.

4 Cf. WHITE, Richard. The middle ground: indians, empires, and republics in the Great Lakes region, 1650-1815. New York: Cambridge University Press, 1991.

$3 I$

revista ieb $n_{47}$ setembro de 2008 
O projeto é sobre então o trabalho da imaginação que articula essas ligações e espaço comum. Entendo imaginação como uma faculdade um pouco rebelde, que anda onde quer, mas sempre ligada à experiência, à matéria e à textura da vida. Nesse sentido, é difícil prognosticar os resultados das trilhas por onde vai a imaginação. Por isso chamo este projeto, de que esta apresentação faz parte, Trilhas perigosas na Amazônia Oriental. Nada é mais evocativo do ambiente onde andam estas passagens que os circuitos dos rios da Amazônia. Os rios e suas margens são a zona de contato. No texto seguinte não vá falar aqui sobre a cultura ligada às águas, gostaria que vocês guardassem em mente a importância e a singularidade desse ambiente.

\section{Cultura popular e religião na Amazônia Portuguesa}

Uma pequena anedota exemplificará minhas intenções. João Felipe Bettendorff era um missionário jesuíta de Luxemburgo e amigo do muito estimado companheiro António Vieira. Bettendorff viveu no Grão-Pará na segunda metade do século XVIII e viajou extensiva e freqüentemente, criando novas missões e supervisionando as já existentes. A sua longa e, por vezes, fascinante crônica do seu trabalho na Amazônia é uma das primeiras peças de escrita da não-conquista: descreve um mundo que, se não completamente em paz, funcionava como uma colônia e uma missão ${ }^{5}$. No início dos anos de 1660, ele ingressou numa viagem de regresso a Santarém (chamada, à época, Tapajós), acompanhado de João Corrêa, um militar que o escoltava e que também já havia estado lá. Depois de uma jornada particularmente fatigante a subir o rio, na qual a sua canoa quase virou durante uma tempestade, ele chega a Santarém ao amanhecer para ser recebido pelos índios. Eles estavam muito agradados por vê-lo novamente. Bettendorff relata:

muito mais por me verem acompanhado de um branco entre eles tão conhecido e amado, pela grande caridade com que os sangrara e curava em suas doenças e achaques, e por esta razão todos chamavam seu atoassanã, que quer dizer compadre. ${ }^{6}$

5 Ainda assim, é importante ressaltar a possibilidade de outras leituras dos detalhes etnográficos que o missionário introduz. A Crônica não apenas documenta a brutalidade da conquista por sertanistas, como também utiliza o modelo da "conquista espiritual" para explicar a missão e a dimensão missionária da colônia.

6 BETTENDORF, J. F. Crônica dos padres da Companhia de Jesus no estado do Maranhão. Belém: Secretaria de Estado de Cultura, 1990. p.164. 
Nada é dito acerca do significado dessa relação para qualquer das partes envolvidas (embora Bettendorff fale de dois homens luso-brasileiros, um deles ex-missionário, que casaram na nobreza índia nativa de Tapajós). $\mathrm{O}$ cronista subentende que o batismo não criava ligação entre as pessoas. Em vez disso, o uso do termo compadre parece ser uma forma amigável de incorporar estranhos no domínio do parentesco. Se tal está correto, o ato está ligado a casos que datam dos primeiros dias da presença européia entre os povos indígenas, quando cronistas registraram a significância da relação atoassanã para os povos indígenas de toda a América do Sul, particularmente para os pertencentes ao grupo lingüístico tupi. Os atoassanãs eram mais do que meros compadres no entedimento nativo: eram pessoas de diferentes grupos (provavelmente primos cruzados) que procurariam estabelecer relações mais abrangentes e duradouras entre os seus parentes. Dessa forma, a relação indígena era uma relação política, que asseguraria laços recíprocos ao longo do tempo. De acordo com Claude Lévi-Strauss, observadores europeus agarravam-se à relação devido à sua semelhança com o compadrio ibérico construído por meio do batismo. Ambos procuravam estabelecer uma nova, especial e artificial ligação. Lévi-Strauss argumenta que o paralelo formal é "um exemplo surpreendente de uma convergência na qual as instituições nativa e latino-mediterrânica mostram numerosas aparentes similaridades que se sobrepõem a importantes diferenças estruturais"

O significado social da expressão de atoassanã (a grosso modo, coparente) em Santarém, na década de 1660, é o reconhecimento de um futuro comum, quer as partes envolvidas o soubessem, ou não. Quaisquer que fossem as diferenças culturais gerais indicadas por Lévi-Strauss, o momento é uma ponte entre dois parceiros, embora desigualmente associados. Revela a importância básica do parentesco para a condução dos assuntos da colônia in situ, quase como uma expressão espontânea. Obviamente, o parentesco encontra-se num dos extremos da escala, com a guerra no outro, e com todos os outros tipos de laços recíprocos que caracterizavam a sociedade do Grão-Pará, no meio. A questão é que estas relações íntimas cresceram apesar do encorajamento ou de restrições, por parte do Estado ou da Igreja, no comportamento dos indivíduos. O argumento de LéviStrauss, porém, é que a convergência só é conseguida devido a um desentendimento que beneficia ambos os lados. Os europeus reconheceram erradamente a instituição nativa de forma a se incluírem e a assimilarem

7 LÉVI-STRAUSS, Claude. The social use of kin terms. In: BOHANNON, Paul; MIDDLETON, John (Ed.). Marriage, family and residence. New York: The Natural History Press, 1968. p. 169. Nota-se que uma das palavras tupis mencionadas por Lévi-Strauss é atourassap, e um dicionário contemporâneo traduz atuasaba como "compadre ou comadre". 
as idéias do grupo indígena. Poderíamos, então, dizer que estava em funcionamento um desentendimento que auxiliou as relações do dia-a-dia e atuou como uma ponte conceitual entre as diferentes tradições.

É possível discutir a cultura popular da mesma maneira? Parte da atratividade do momento ataossanã é a imagem que nos dá de um grupo de pessoas numa praia arenosa fluvial, olhando uns para os outros, rindo e conversando. Podemos imaginar outros momentos de ligação que tenham pouco a ver com o parentesco, e sim com o partilhar de contos populares, de mitos, de Portugal e indígenas? Talvez possamos - por baixo das estrelas de uma quente noite tropical, bebendo cachaça, ou conjuntamente lavando roupas nessa mesma praia, ou ainda durante intimidades sexuais na floresta. Meu objetivo aqui é tentar posicionar a análise em locais reais, entre pessoas vivas, trabalhando na fronteira de suas imaginações.

Minha proposta é que a miscigenação étnica e do parentesco também envolveu a construção (e a ponte conceptual) de formas de pensar, na cultura popular, ligando noções de hibridação religiosa, a relação entre indíviduos e o Estado Colonial, e, no caso da minha temática, as relações e pontos de contato entre o folclore e o imaginário europeu e indígena. Nesse terreno, ou fronteira, idéias e imagens aproximam-se, colidem ou convergem, absortas de hierarquias sociais, políticas, econômicas ou raciais existentes. Como resultado, o estudo dessa "fronteira imaginativa" ajuda a entender a complexidade das dinâmicas de interação social num ambiente colonial, afastando a discussão de uma dicotomia simplista entre negro/ mestiço e branco, ou índio e europeu. Em outras palavras, o trabalho da imaginação nesses contextos possibilitou o reconhecimento do outro.

A fonte principal para o estudo da religião popular na Amazônia nos períodos coloniais é a "visitação" da Inquisição ao Grão-Pará em 1763$1799^{8}$. Adicionalmente, há um número de processos na Torre do Tombo que estão fora da "visitação" ao Pará e que revelam um caráter mais fascinante e menos investigado da Amazônia portuguesa. Uma historiadora que fez bom uso dos registros (incluindo os de Belém), de forma a mostrar que o Grão-Pará no século XVIII apresentava tanto semelhanças como diferenças com o resto do Brasil, foi Barbara Sommer. Ela examina uma série de casos que trazem magia e bruxaria envolvendo amor e sexo, e argumenta que "através de uma troca livre de ritos populares e a retenção de práticas indígenas, os paraenses contrariaram os esforços das autoridades

8 Amaral Lapa transcreveu o Livro da visitação, o qual contém quarenta e sete confissões e denúncias. Não traz os julgamentos: somente alguns dos casos levados ao Inquisidor chegaram tão longe. Os registros dos julgamentos guardados na Torre do Tombo, em Lisboa, contêm o interrogatório do acusado no que se refere às alegações, a sua genealogia, e o resultado do processo. 
da metade do século para promover a identidade nacional portuguesa e moldaram uma cultura única regional"'. Em outras palavras, as pessoas atuavam nos seus próprios interesses, independentemente do que o Estado queria $^{10}$. (Veja-se também Almir Diniz de Carvalho Junior, sobre religião indígena que usa a Inquisição de Lisboa, entre outras fontes. ${ }^{11}$ )

Um estudo mais abrangente da natureza colonial das atividades religiosas no Brasil tem sido bem realizado por Laura de Mello e Souza. Ela escreve que havia "convivência e interpenetração de populações de procedências várias e credos diversos. Múltiplas tradições culturais desaguavam, assim, na feitiçaria e religiosidade popular. Dar conta dessa complexidade significava compreendê-la como o lugar em que cruzavam e reelaboravam níveis culturais múltiplos agentes de um longo processo de sincretização" ${ }^{12}$. Laura de Mello e Souza enfatiza, ao longo do seu estudo da feitiçaria, a existência de "um fosso enorme" ${ }^{13}$ que separaria a crença e prática religiosa popular e a oficial, particularmente a Inquisitorial. Argumenta que a incorporação de elementos populares ou sincréticos do passado, e de outros continentes, não ocorreu por osmose, mas foi modelada pela vida na colônia. Tais elementos não eram sobrevivências: sua presença "era vivida, inseria-se neste sentido, no cotidiano das populações. Era, portanto, vivência" ${ }^{14}$. Todavia, falta ao estudo de Mello e Souza uma contextualização etnográfica da religiosidade colonial, que revelaria como esses elementos faziam parte das vidas diárias e dinâmicas sociais.

Há mais um ponto de partida. Carlo Ginzburg, no ensaio sobre "o antropólogo como inquisidor", nota que um valor dos processos da Inquisição é trazer as vozes dos réus direto para nós. A testemunha mesmo, enquadrada no contexto do poder extremo da igreja e do estado, é recordação fiel do que foi dito. Sobretudo, a interrogação do inquisidor era uma tentativa de saber se houvera ou não heresia, e isso necessitava uma recordação exata das palavras ditas. $\mathrm{O}$ inquisidor estudaria a transcrição com atenção minuciosa aos significados. Aqui não vou usar os registros da

9 SOMMER, Barbara. Cupid on the Amazon. Colonial Latin American Historical Review, v. 12 , n. 4, p. 415-446, 2003. p. 416.

10 Idem. Cupido na Amazônia: amor e moralidade em finais do século XVIII no Pará. In: NIZZA DA SILVA, Maria Beatriz (Org.). De Cabral a Pedro I: aspectos da colonização Portuguesa no Brasil. Porto: Universidade Portucalense Infante D. Henrique, 2001. p. 131-141; SOMMER, Barbara. Cupid on the Amazon. Op. cit.

11 CARVALHO JR., Almir Diniz de. Índios cristãos: a conversão dos gentios da Amazônia Portuguesa (1653-1769). 2005. 402 f. Tese (Doutorado em História) - Instituto de Filosofia e Ciencias Humanas, Universidade Estadual de Campinas, Campinas, 2005.

12 MELLO E SOUZA, Laura. de. O Diabo e a Terra de Santa Cruz: feitiçaria e religiosidade popular no Brasil colonial. São Paulo: Companhia das Letras, 1986. p. 16.

13 Ibidem. p. 149.

14 Ibidem. p. 98-9. 
Inquisição no Grão-Pará, mas um processo jurídico que também nos traz as vozes do passado. Analisarei um caso judicial do interior da Amazônia. Creio podermos fazer importantes generalizações sobre a Amazônia portuguesa do fim do século XVIII. Também aqui sigo o conselho de Ginzburg: em algumas circunstâncias, a leitura muito próxima e intensa de um só texto do arquivo vale mais do que a acumulação infinita da matéria repetida e chatíssima!

Meu argumento consiste em que, com base nestas ligações, a inteligibilidade da referência ao lobisomem representa uma fronteira imaginativa $^{15}$. Essa fronteira era uma convergência muito localizada de diversas mentalidades de diferentes atores, nesse caso, no que diz respeito às metamorfoses de humanos e animais. Muito dependente do caráter das relações locais, era, por isso, regionalizada e heterogênea. Essa fronteira entre mentalidades foi a forma pela qual brancos, mestiços e índios acabaram por se compreender e construir um modo de vida distintamente amazônico ${ }^{16}$.

\section{Aspectos do contexto histórico}

A matéria examinada a seguir encontra-se em um documento que consta do Arquivo Público do Pará, em Belém. Na verdade, é um maço de documentos consistindo de uma longa carta escrita de uma pequena vila, chamada Vila Franca, por José Cavalcante de Albuquerque, com data de 31 de março de 1793, ao governador do Estado, Francisco de Souza Coutinho, e dois "autos de justificação" realizados nas vilas de Santarém e Óbidos, em meados de março de 1793. Esses três lugares, existentes desde então, situam-se na área do Baixo Amazonas e vêm, portanto, desde a época do Estado do Grão-Pará. Para os que não têm contato com a realidade dessa região, vale mencionar que Santarém se situa na foz do Rio Tapajós, Óbidos a cerca de dois dias de viagem subindo o rio Amazonas em canoa movida a remo, e Vila Franca na foz do rio Arapiuns, a uma distância de um dia de viagem partindo de Santarém na mesma forma de transporte.

15 Sobre o trabalho de imaginação, veja RICOUER, Paul. Historiography and the representation of the past. In: GIFFORD, Paul (Org.). 2000 years and beyond: faith identity and the common era. London: Routledge, 2003. p. 51-68. p. 171.

16 Um argumento semelhante é apresentado por Carolyn Podruchny para o Canadá colonial francês e, por coincidència, envolvendo, igualmente, a figura européia do lobisomem (PODRUCHNY, Carolyn. Werewolves and windigos: narratives of cannibal monsters in French-Canadian voyageur oral tradition. Ethnohistory, v. 51, n. 4, p. 677$700,2004)$. Recorrendo a narrativas do século XIX sobre o lobisomem e o windigo (um monstro canibal Algonquian), ela revela "um complexo movimento cultural, uma mescla de cosmologias e tecnologias orais" entre os viajantes franco-canadenses e as suas mulheres aborígenes e parentes. 
Todavia, são comuns nos documentos do período, incluindo os da Inquisição no Pará, indiciações concernentes a comportamentos inadequados relacionados com magia e feitiçaria. Tais documentos estão cheios de acusações e contra-acusações envolvendo práticas e crenças. Devemos ver todas essas acusações mais genericamente, incluindo a aqui analisada, como acusações típicas de bruxaria. Elas são, fundamentalmente, acerca das dinâmicas sociais num contexto particular; não podem ser facilmente usadas como forma de compreender em que as pessoas acreditavam e em que pensavam. Em outras palavras, precisamos primeiramente compreender o contexto histórico e, em seguida, reconstruir os elementos que deveriam estar posicionados a fim de que tal acusação fizesse sentido para os participantes locais.

\section{Contexto político}

De modo sumário, apresentarei em seguida um esboço dos principais fatores que modelavam o mundo da localidade no final do período do diretório e do século XVIII. Este é um tópico muito amplo e procurarei limitar-me ao que é mais pertinente, ou seja, à organização das relações entre indígenas e europeus. Por conta de sua presença marginal nesta narrativa, preciso deixar de lado o papel dos africanos escravizados. Entretanto, eles faziam parte do contexto maior e contribuíram para a cultura amazônica.

A legislação do diretório foi escrita por Francisco Xavier de Mendonça Furtado, irmão do Marquês de Pombal, em 1755, mas somente começou a vigorar em 1757, protelamento causado pela oposição dos jesuítas, fator este da dimensão amazônico de um fenômeno mais geral que lhes causou a expulsão em 1759. O diretório e as reformas a ele ligadas tinham por objetivo reformar a região segundo linhas progressistas. Entre seus mais importantes aspectos, destacam-se: a garantia de liberdade aos índios, a secularização da vida cotidiana, a promoção de casamentos entre colonos e índios pelo oferecimento de incentivos econômicos, a instalação de escolas em cada aldeia, o uso exclusivo da língua portuguesa (ao invés da língua geral usada pelos missionários) e a alocação de incentivo de lucro aos indígenas na produção econômica de uma aldeia. Esses eram os dias otimistas do iluminismo ibérico; o desenvolvimento da Amazônia era considerado fundamental para as estratégias geopolíticas do Império Português. Acima de tudo, o diretório era destinado a reestruturar a economia para atender as necessidades do estado e converter os índios das missões em vassalos adequados da Coroa, por meio de sua civilização e, é preciso 
acrescentar, de sua transformação à condição de camponeses ou "vassalos", nos termos da época.

A realidade jamais conseguiu concretizar o modelo projetado. $\mathrm{O}$ interesse privado dos colonos sobrepôs-se ao interesse público e os índios jamais conseguiram a liberdade que lhes fôra prometida. As cifras indicativas da produção jamais se elevaram o bastante para obter a renda que permitiria criar um sistema burocrático local para fiscalizar as atividades dos colonos e mercadores e as influentes elites administrativas. $\mathrm{O}$ governador Souza Coutinho, o mesmo a quem nos referimos inicialmente, desmantelou o sistema administrativo em 1799, colocando a culpa na preguiça dos índios e na impossibilidade de controlar os diretores e outros oficiais ${ }^{17}$.

Por volta da década final do século XVIII, o diretório vivia os seus últimos momentos do ponto de vista da administração metropolitana. Muitos diretores estavam seqüestrando a produção comunal para seu próprio benefício. Índios estavam em controle de várias vilas, como Vila Franca, Alter do Chão no Baixo Amazonas, e outros no Marajó ${ }^{18}$. Os africanos fugiam com freqüência e facilidade e formavam mocambos. O poder do Estado, mesmo estabelecido em toda a região vasta, era frágil e ameaçado por diversos interesses.

Vale a pena mencionar rapidamente o governador que aboliu o diretório. Francisco de Souza Coutinho era de uma família importantíssima do fim do período colonial. O pai era governador de Angola, os irmãos mais velhos ocuparam as posições mais altas em relação ao Brasil. Então, ele era bem posicionado para impor reformas com o apoio do centro, igual a seu contrapartido, Francisco Xavier Mendonça Furtado, o irmão do Marquês de Pombal. Ambos os governadores merecem mais atenção, mas ao que sei não há quase nada escrito desses homens. Durante seus treze anos (1790-1803) no Pará, Souza Coutinho aumentou a importação dos escravos, começou um programa de construção de navios e fez reformas militares. No fim do século XVIII, Belém era o quinto porto do Brasil em nível de exportações

17 Na verdade, o Governador Souza Coutinho já havia tido problemas com Vila Franca em 1790, quando um posto de fiscalização em Gurupá apreendeu uma canoa vinda da cidade. A canoa levava mercadorias produzidas em comum, que deviam, porém, ser vendidas para o lucro pessoal do diretor, de acordo com o testemunho do cabo de canoa. O diretor, Antônio José Malcher, foi expulso da cidade. O Governador ficou tão zangado, que deu ordens para que nenhum auxílio fosse dado a esse homem com a remoção de sua família e do extenso séquito formado pela sua propriedade de bens e de escravos. Mas essa ordem não foi cumprida, porque a autoridade em Santarém teve pena do ex-diretor, deixando a impressão de que ou estava em conluio com ele, ou concordava com a transgressão. A expulsão levou o Governador Souza Coutinho a nomear José Cavalcante como substituto.

18 Cf. SOMMER, Barbara. Cupido na Amazônia: amor e moralidade em finais do século XVIII no Pará. Op. cit. p. 131-141. 
e importações. Tal crescimento era devido à produção de cacau por escravos nas áreas do Baixo Amazonas e Tocantins. Podemos refletir que a crise que provocou o fim do diretório não era geral. O Pará no fim do século XVIII vivia um momento bom.

Muito mais poderia ser dito a respeito do que se passava nos bastidores. Prefiro resumir aqui que esses foram tempos de confronto e reconstituição. Após um século de destruição cultural e física das formações ameríndias ao longo do grande rio, de 1650 a 1750, os diversos atores encontravam-se enredados entre as severas regulamentações do diretório e, ao mesmo tempo, o amplo espaço sem lei que era o imenso território à sua disposição. Entre esses extremos, evoluíram os distintos e localmente diversos mundos da Amazônia Colonial. Quase por acaso e certamente sem nenhum planejamento, a capacidade inovadora e pragmática de cada indivíduo veio a alcançar um significado essencial na luta pela sobrevivência. Aqui, indígenas, europeus e seus descendentes já nascidos nas novas terras, portanto, os primeiros "brasileiros", eram transformados por suas experiências, usando os recursos culturais que lhes estivessem à mão para compreenderem a realidade presente com que se confrontavam. É nesse contexto da experiência compartilhada (se diferentemente interpretada) e das séries emergentes e instáveis de significados e símbolos que precisamos colocar a estória do lobisomem de Vila Franca. Desejo chamar esse espaço reconstituído de "uma fronteira da imaginação", em que os tentáculos perceptivos de cada pessoa buscam as ligações entre o passado e o presente.

\section{O justificante}

Agora algumas palavras sobre o justificante, nosso lobisomem. José Cavalcante de Alburquerque nasceu na Bahia em 1760. Graduou-se na Universidade de Coimbra em 1785, em Direito e Matemática ${ }^{19}$. Nomeado diretor de Souzel, vila do rio Xingu, em 1787, depois foi como diretor dos índios em Vila Franca, em 1790. A razão por que procurou uma nomeação no Pará não é óbvia, mas pode ter sido a ambição e a busca de terra. Em 1801 era Juiz de Paz em Óbidos e capitão dos milicianos ligeiros, um novo e temporário exército (o qual se pode entender por força de trabalho) trazido para substituir o sistema de recrutamento de trabalho indígena dos diretórios. Em 1819, ele era descrito como dono de escravos nos registros batismais da paróquia de Óbidos. Também possuía gado, uma plantação de

19 MORAIS, Francisco, Estudantes Brasileiros na Universidade de Coimbra (1772-1872), Anais da Biblioteca, LXII, 1940, p. 137-335. 
cacau e um comércio. Tinha quatro filhos batizados em Óbidos e casou-se com Rita Vitória Alburquerque antes de 1812 (no censo de 1792 aparecia listado como solteiro). Então, no auge de sua carreira, em dezembro de 1821, foi eleito deputado da Capitania do Rio Negro para as Cortes Reais Portuguesas e viajou para Lisboa em agosto de 1822; 77 deputados, no total, foram eleitos no Brasil. No entanto, ele foi substituído como deputado em 1823 e procurou, alternativamente, fundos para um projeto que visava a educar os índios no Rio Negro. Com o apoio do bispo do Pará e de outros deputados do Norte do Brasil, seu objetivo era incentivar os índios a se assentarem em aldeias e a trabalhar. Creio que o programa fazia parte de uma nova onda na civilização dos índios, que venha da relação mais antiga que tinha com o governador Souza Coutinho, que escreveu um Plano de civilização na época da desmontagem do diretório ${ }^{20}$. O plano de Cavalcante não recebeu nenhum apoio, e, em agosto de 1825, ele ainda se encontrava escrevendo cartas para requerer fundos que o levassem de volta para a Amazônia ${ }^{21}$.

Ele inicia a carta de onze páginas ao governador em $1793 \mathrm{com}$ a declaração: "não havendo a natureza o feliz acidente de hum nobre [nascimento]; devi Providência huma educação hum pouco onesta”. Assim começa o seu apelo ao Governador, o qual o tinha anteriormente elogiado pelos seus bons trabalhos e inteligência. A carta oferece uma série de eventos de sua história, de forma convincente e bem argumentada, os quais abordarei em seguida. Ele também critica o diretório e requer o seu fim - "hum Director hum tirano", acrescentando que ninguém se beneficia das suas regras. O seu raciocínio é que é impossível ter índios a trabalhar para a produção comum: eles fogem da aldeia, e os oficiais locais, tal como o cabo da canoa, não registram corretamente o que é produzido; e a punição não é a solução. Como diretor de Vila Franca, ele teve lutas constantes porque ninguém lhe obedecia. Os índios eram "monstros de ingratidão" e ele queria "com algum barril do sol moira tapar a boca ao tezoureiro com o seu escrivão". Termina a sua carta com um apelo ao governador para

20 SOUZA COUTINHO, Francisco, Plano de civilização, Arquivo Histórico Ultramarino [AHU] Pará 8610, 1797, August 3rd, Pará.

21 NIZZA DA SILVA, Maria Beatriz (Org). Dicionário da história da colonização portuguesa no Brasil. Lisboa: Verbo, 1994. p. 243-246; BAENA, A.L.M. Compêndio das eras da Província do Pará. Belém: Editora da Universidade Federal do Pará, 1969. p. 345. (Coleção Amazônica. Série José Veríssimo); RAIOL, D.A. Motins políticos, ou História dos principais acontecimentos politicos da Provincia do Pará desde o ano de 1821 até 1835. Belém: Editora da Universidade Federal do Pará, 1970. p. 21.3 tomos; Arquivo Histórico Ultramarino [AHU] Pará, caixa 159, doc. 12129; AHU Pará, caixa 161, doc. 12283; AHU Rio Negro caixa 18, doc. 750; Paróquia de Óbidos, Livro de Baptismos 1807-1820. 
passar três dias na sua aldeia como diretor, de forma a ver como é difícil cumprir a legislação. Ele está "cançado [para] poder viver com elles [segundo] o seu passado, e [para] profundar os seos gênios, e costumes" Apesar dessas dificuldades e dos boatos contra ele, o seu espírito não desvanesceu, e ele prosseguirá. Mas "nada”, ele reassegura ao governador, "pode chamar invenção do seu Director" ${ }^{23}$.

\section{As alegações e os índios}

Eis o que foram as alegações contra Cavalcante no processo jurídico. Três delas estão descritas nas páginas iniciais do auto perante a "inquirição", isto é, os depoimentos das testemunhas:

Ele é acusado de beber em demasia, "vício da bebida".

De ser um mau administrador, negligente em relação a cuidar dos índios, de passar a maior parte do tempo no seu cacaual e por acobertar um criminoso, alguém que já fôra expulso de vários lugares, por quebrar o sossego público e comportar-se de modo indevido ("má conduta").

E finalmente, existe uma acusação do Vigário de Vila Franca, Domingos de Lira Barros, de que ele costumava aparecer à noite como um "lobisomem" ou outras figuras semelhantes e, desse modo, abusar da ignorância e superstição de índios sob sua guarda e de alguns brancos.

É sobre o terceiro item que me concentrarei, deixando de lado os outros dois. Claro, entretanto, que deveria ser lembrado, durante todo o processo, que a acusação de ser esse homem um lobisomem faz parte de um episódio mais amplo subjacente à crise.

Até onde pude apurar, José Cavalcante conseguiu limpar o seu nome. Todas as testemunhas disseram que ele não era muito dado a beber, ingerindo somente, às vezes, uns poucos copos de vinho. Ele era forçado a passar tempo no seu cacaual devido às más relações locais. A maioria das declarações das testemunhas condenam as ações dos dois indivíduos acima mencionados, o clérigo e o tesoureiro; o cabo da canoa também estava envolvido.

No coração do caso está o papel dos índios; no entanto, não ouvimos as suas vozes. Nesses documentos, há duas versões da participação índia. Já apontamos a visão dominante, de que os índios eram seres simples.

22 A única referência de Cavalcante às acusações de "lobizome" foi quando ele descreveu que o cabo da canoa, Antonio Coelho, escreveu que ele era uma "cabeça de fogo".

23 APEP códice 501 doc. 6, 31 março 1793, José Cavalcante de Albuquerque. 
Adicionalmente, encontramos nas declarações a indicação de que os oficiais inferiores (acima mencionados) de Vila Franca teriam encorajado os índios a desobedecerem a Cavalcante. Estas pessoas, Antonio Coelho e João Rodrigues Pereira, eram conhecidas por terem sido expulsas de outras vilas por comportamento anti-social e, realmente, no tempo do "auto", já haviam desaparecido da área.

Por outro lado, o mais sensível José Cavalcante mencionou na sua carta ter ajudado uma índia que havia sido abusada (provavelmente violada) na sua roça por um homem índio. Ele a protegeu, colocando-a na sua casa no cacaual. É possível que isso tenha incitado um novo antagonismo, ou que fosse parte de uma disputa preeexistente. Ele também menciona que os índios eram muito poderosos e queriam governar a cidade, por isso não lhe obedeciam. Em outras palavras, os índios não eram tão passivos como indicado pelas testemunhas. Devido ao grande número de índios e ao pequeno número de portugueses e brasileiros, e às suas evidentes divisões, não é provavelmente incorreto pensar que os índios estariam a controlar muito da atividade da vila. É freqüentemente salientado por historiadores que o trabalho e a produção eram as principais dificuldades do período colonial da Amazônia Portuguesa. Essas eram extremamente importantes e Cavalcante o testemunha. Porém, é claro que esses problemas estavam interligados a outros fatores, como as lutas locais de poder, as quais eram mais sutis do que uma estrutura índios versus brancos.

Não é possível compreender a acusação contra o "lobisomem" sem o contexto detalhado no qual ela ocorria. O sociológico e o imaginativo estão claramente articulados na investigação. Então, é tempo de passar a uma consideração do lobisomem e de suas características.

\section{O "auto da justificação" e o "lobizome" em Vila Franca, Grão-Pará, 1793}

Conforme compreendi, um "auto de justificação" é solicitado por uma pessoa que deseja limpar o seu nome de várias acusações. O juiz ordinário da vila convida várias testemunhas para falar a favor ou contra o "justificante" e a respeito das acusações que lhe são imputadas. Por essa razão, este envia os autos acompanhados de sua carta ao Governador do Estado (naquela época, o governador era Francisco de Souza Coutinho), o qual teria a palavra final no julgamento dos resultados do auto: as acusações eram ou não justificadas ${ }^{24}$

24. Estes tipos de acusação são freqüentemente encontrados nos "autos de justificação", embora eu nunca tenha anteriormente descoberto uma que envolvesse a referência ao lobisomem ou a uma figura semelhante. Normalmente uma justificação se refere 
O juiz ordinário de Óbidos, Estanislau Ferreira, apresenta do seguinte modo a posição do suplicante:

e também se lhe necessaria mostrar se o Reverendo Domingos de Lira Barros que foi de Villa Franca fez persuadir não so a todas os indios della, que o suplicante era lobizome de cujo epiteto de mana tem tantos abusos servindo-se desta diabolica superstição, ignorancia dos indios, que os seos sinistros fins. ${ }^{25}$

O juiz de Santarém, Marcante, fez a mesma colocação.

Em cada caso, o juiz ordinário tem de argüir testemunhas, o escrivão registra-lhes as respostas. $\mathrm{O}$ que as testemunhas disseram a respeito de José Cavalcante de Albuquerque ser um lobisomem? Das sete chamadas em Óbidos, quatro tiveram algo a dizer sobre o assunto. O primeiro, um sesmeiro de 63 anos, Constantino Manoel Marinho, expressou-se de modo bastante claro:

Diçe mais em quanto abominavel abuzo de lobizome que o Reverendo Vigario no que foi de Villa Franca Domingos de Lira Barros emtroduzia na rusticidade de queles povos em discredito de Seu Diretor para os fins que elle so saberia lhe consta assim ter sido por lhe referir em varias ocasions algumas indias.

O padre havia inventado que José Cavalcante era um lobisomem e, ao assim fazer, não apenas explorava a vulnerável simplicidade dos indígenas, mas também levava Cavalcante ao descrédito. Afinal, quem iria aceitar ordens de um lobisomem? Contudo, ele apenas ouvira isso dos índígenas da área.

A segunda testemunha, Vicente Marinho, filho da primeira testemunha, de 31 anos de idade, casado, confirmou o padre como origem da história:

Diçe mais ao abuso que o Padre Domingos de Lira Barros emtroduzia no fraco e rusticos animos dos indianos de Villa Franca dizindo ser o Diretor era lobizome que se transformava em defrentes figuras que sabia por uma garuta em leva rodas de fogo e outros semelhentes delirios.

a assuntos mundanos tais como alegações de corrupção, roubo, mau comportamento, entre outras. A única maneira para alguém se proteger de tais alegações seria entrar no processo judicial, convocar testemunhas e aguardar pelo veredito do governador do estado. Confira-se o romance de SOUZA, Inglês de. $O$ cacaulista. Belém: UFPa, 2004, para ver mais sobre a conduta dos processos nos meados do século XIX, que não poderia ser tão diferente do fim do século XIX.

25 APEP códice 501 doc. 06, 31 de março 1793, José Cavalcante de Albuquerque. 
Portanto, José Calvacante, segundo os seus detratores, não apenas virava lobisomem, mas também outros tipos de seres, inclusive uma roda de fogo.

O terceiro testemunho de Óbidos foi dado por José Dias da Silva, casado e de 31 anos de idade. Corroborou as declarações anteriores, introduzindo, porém, uma importante diferença:

Diçe mais que em quanto ao abuso que emtroduzia Padre Domingos de Lira Barros na rusticidade dos indios her serto pois que aelle mesmo testemunha lhe sertificar contados as vezes de que o suplicante hera lobizome e se transformar de noite em varias figuras.

No meu entender, ele dissocia a fonte do boato, o padre, do boato em si mesmo; José Cavalcante poderia muito bem tomar outras formas, acontecendo que o fato se tornou conhecido devido à tentativa do padre de desacreditá-lo.

As declarações provenientes de Santarém têm fraseado diferente e oferecem outra perspectiva da história. Há três testemunhas de Santarém. A última testemunha a fazer um comentário substancial é um tal Manoel Pinto, que assinou com uma cruz, visto não saber escrever

E porguntado delle testemunha pello contheudo requirimento do justificante disso indo digo que indo elle testemunha a Villa Franca no tempo em que era Vigario o Padre Domingos de Lira Barros e indo elle testemunha vizitalo, o ditto Vigario nam sessou de lhe falar mal do ditto Diretor e Justificante dizendo lhe era mao e que era lobizome e que de noite quando mudava de figura batava muito fogo pelos olhos e que tambem lhe diçeram algumas peçoas que o ditto Vigario se embriagava muitas vezes e que sempre era custumada a isso.

De todas as pessoas chamadas a oferecer evidência, Manoel Pinto foi o único que teria falado com o Vigário. Este parece ter ido embora (teria sido removido?) na ocasião em que se realizava a investigação ${ }^{26}$.

26 Antes de considerar em profundidade este material específico e seu contexto, eu deveria acrescentar que, até onde posso dizer, José Cavalcante conseguiu limpar o seu nome. Conforme foi apurado dos depoimentos, ele não era viciado em bebida, apenas tomava "uns cálices de vinho", às vezes. E também ele era forçado a despender tempo em sua plantação de cacau por causa dos maus relacionamentos locais. A maioria das declarações das testemunhas são de fato destinadas a esclarecer os complicados negócios e relações entre os vários indivíduos, a fim de demonstrar que o queixoso nada havia roubado, nem tentara esconder os níveis de produção de Vila Franca. De qualquer modo, José Cavalcante ressurge em algumas outras cartas mais adiante, e não pude achar nenhuma carta do Governador Souza Coutinho que o censurasse pelo seu comportamento. 
Desejo chamar a atenção para dois aspectos distintos da evidência acima apresentada. Primeiro, o de que havia um conflito entre o Vigário e o Diretor, que se expressou, pelo menos nesse auto, na evocação de uma figura diabólica originada no folclore europeu. Essa tensão está relacionada, no documento, à rusticidade dos índios. José Cavalcante quer provar que era o Vigário quem propositalmente explorava a rusticidade dos indígenas, a fim de os amedrontar e a persuadi-los a tomarem partido na disputa pessoal entre os dois homens.Tipicamente, isso implica um argumento bastante paternalista, no que diz respeito à inteligência dos nativos. Em segundo lugar, há a alegada capacidade de José Cavalcante em "virar", ou gerar, uma série de "defrentes figuras" (construção arcaica que significa "diferentes figuras"), inclusive a de lobisomem. Relacionados a isso estão os intrigantes detalhes da "roda de fogo" e "os olhos que batava de fogo". De um lado, têm-se relações pessoais carregadas e a manipulação de várias pessoas, moldada pelo caótico contexto sociológico e colonial. De outro lado, encontramos o que poderíamos chamar, a grosso modo, de crenças e idéias relacionadas com a transformação corpórea, provavelmente originadas tanto da tradição européia como da indígena. Tenho o cuidado de dizer provavelmente, porque nada sabemos das outras figuras em que Cavalcante era acusado de transformar-se. Considerando a repressão aos elementos indígenas, introduzida com as reformas pombalinas da metade para o final do século XVIII, é possível que administradores em ascensão ficassem relutantes em mencioná-los numa carta ao Governador (que, na verdade, terminou por extinguir o diretório, devido à falha dos administradores locais em fazerem cumprir as leis e a vontade dos regentes reais).

Na verdade, dos muitos documentos e cartas despachados do Baixo Amazonas no período colonial e nos primórdios do Império, esse auto é o único que encontrei que faz menção ao fundamento religioso ou folclórico de crenças. A grande maioria discute produção e organização econômica, o movimento de pessoas e de equipamento militar; é patente serem esses os assuntos de interesse maior na comunicação entre os níveis locais e estaduais de administração. Conforme mencionei acima, a maior parte do auto enfoca essas questões. A atenção marginal dada às acusações de "lobisomem" nesse documento oficial ganha importância por ser fora do comum e, até onde consegui pesquisar, não tem precedentes. Em outras palavras, a natureza formulizada que caracteriza muitas das declarações das testemunhas é menos forte do que nos assuntos centrais da cadeia burocrática. Por essa razão, os testemunhos relacionados com o lobisomem revelam a existência de significativos processos em andamento, que, a meu ver, descrevem as aventuras mentais alimentadas pelas fronteiras da imaginação inspirada pela vida colonial. 


\section{O lobisomem, a cumacanga e outros seres transformacionais}

As figuras do lobisomem sobreviviam na Europa do século XVIII, e na verdade, de acordo com Luís da Câmara Cascudo, floresciam na França do século XVII ${ }^{27}$. Carlos Rocque, em sua Grande enciclopédia da Amazônia, assim define o lobisomem daquela região:

Espírito mau, monstro (homem que à noite se transforma em lobo). Mesmo não existindo o lobo na Amazônia, esta é uma das lendas que mais se difundiram e permite avaliar a grande influência de outros grupos na formação étnica brasileira. ${ }^{28}$

Câmara Cascudo considera universais os mitos em que lobos e humanos aparecem relacionados; a versão brasileira deriva claramente da cultura ibérica, em que virar lobo é castigo por ofensa moral grave, como, por exemplo, o incesto. Também menciona uma variação amazônica do mito do lobisomem chamada de cumacanga no Pará: uma encarnação especial do lobisomem, visto que não se trata do sétimo filho ou do produto de uma relação incestuosa, mas do filho resultante de uma relação sexual ilícita e sacrílega de um padre. A cumacanga não fica assombrando a vizinhança como o lobisomem. Em vez disso, numa noite de sexta-feira, o corpo da pessoa permanece na casa, enquanto a cabeça se desprende e se transforma numa bola de fogo voando pelo céu e voltando várias vezes ao local onde o corpo se encontra. Essa versão da história do lobisomem parece só existir no Maranhão e no Pará. Também parece possível que o testemunho a respeito dos olhos de fogo e da roda de fogo seja uma referência ligada ao complexo da cumacanga, se não pelo nome, pelo menos pela aparência e fundamentação.

27 Sobre lobisomens ou werewolves a literatura é extensa. Vejam-se, por exemplo: CÂMARA CASCUDO, Luís da. Geografia dos mitos brasileiros. São Paulo: Global, 2002; LADURIE, E. Le Roy. Jasmin's Witch: an investigation into witchcraft and magic In South-West France during the Seventeenth Century. Trans. by Brian Pearce. Harmondsworth: Penguin, 1990; os contos da feminista e romancista CARTER, Angela. The bloody chamber and other stories. London: Vintage, 1995; GINZBURG, Carlo. Clues, myths and the historical method. Trans. J. e A. Tedeschi. Baltimore: The Johns Hopkins University Press, 1989; Ecstasies: deciphering the witches' Sabbath. trans. by Raymond Rosenthal. Harmondsworth: Penguin Books, 1992; VAZ DA SILVA, Francisco. Iberian born seventh born children, werewolves, and the dragon slayer: a case study in the comparative interpretation of symbolic praxis and fairytales. Folklore, v. 114, p. 335-353, 2003; JACQUES-LEFEVRE, N. Such an impure, cruel, and savage beast... In: EDWARDS, K. (Org.). Werewolves, witches and wandering spirits: traditional belief and folklore in early Modern Europe. Kirksville, Missouri: Truman State University Press, 2002. p. 181-198. (Sixteenth century essays and studies series, v. 62).

28 ROCQUE, Carlos. Grande enciclopédia da Amazônia. Belém: Amazônia Editora, 1966. 
No período em questão, a língua geral era falada em toda parte no Grão-Pará, embora Mendonça Furtado na década de 1750 haja tentado proibir o uso dessa língua. Para se comunicar, quase todo mundo no interior teria de entender e conversar em língua geral. Cumacanga tem origem na língua geral e é composta de duas palavras. No meu entendimento não está claro se a primeira palavra é $c u n h a ̃$, mulher, ou $c u$, língua. O segundo termo é cabeça (acanga), com certeza. Pelo menos, cabeça é um elemento central. Se é uma cabeça de mulher ou uma cabeça com línguas de fogo, não sei. Podemos ver isto na exposição seguinte.

Dois outros seres míticos existentes no Brasil envolvem fogo. A anhanga é um espírito mau que protege os animais na floresta; em algumas versões, tem olhos de fogo. Pode transformar-se em qualquer animal, incluindo humano, e faz os caçadores se perderem. O curupira é uma entidade da floresta às vezes descrita com cabelo de fogo. A mula-sem-cabeça é a figura metamorfoseada de uma mulher, a amante de um padre. A transformação, a qual ocorre das noites de quinta para as manhãs de sexta-feira, é uma punição por transgressão moral; parece que o padre não é punido. A mula-sem-cabeça faísca fogo do seu pescoço e dá coices com muito relinchar, possuindo, portanto, alguma semelhança com o lobisomem e com a cumacanga. A história é generalizada na Península Ibérica e tem também várias manifestações na América Espanhola ${ }^{29}$.

A única referência contemporânea do documento acha-se na crônica dos cientistas bavarianos Karl Martius e Johann Spix ${ }^{30}$. Em sua discussão sobre o medo de entidades diabólicas pelos índios, falam da equivalência entre um encantado e o lobisomem de origem portuguesa ${ }^{31}$. O encantado parece um homúnculo e também um tipo de cão com orelhas bem longas, que faz muito barulho à noite. Mas eles falham ao contar a lenda portuguesa. A crônica continua informando que a equivalência é ligada à similaridade entre os contos dos índios sobre o boitatá (rodas ou cobras de fogo) e o que os portugueses entendem como a mula sem cabeça ${ }^{32}$. A discussão

29 CÂMARA CASCUDO, Luís da. Op. cit. p. 191-195.

30 Há poucos trabalhos sobre a vida religiosa no período do diretório da Amazônia colonial; as melhores fontes são as duas visitas pastorais de Queiróz (SÃO JOSÉ QUEIRÓZ, D. Fr. João de. Viagem e visita do sertão em o Bispado do Gram Pará em 1762-3. Revista do Instituto Geográfico e Histórico Brasileiro, tomo 10, p. 43-107, 179-227, 328375, 476-527, 1848; CASTELLO-BRANCO, Camillo. Memórias de Fr. João de São José Queiróz, bispo do Grão-Pará. Com uma introdução e notas illustrativas por Camillo Castello-Branco. Porto: Typographia da Livraria Nacional, 1868) e os documentos inquisitoriais transcritos por Amaral Lapa (AMARAL LAPA, R. (Org.). Livro da visitação do Santo Ofício da Inquisição ao estado do Grão-Pará. Petrópolis: Vozes, 1978).

31 SPIX, Joham B. von e MARTIUS, Karl. Viagem pelo Brasil, 1817-1820. Belo Horizonte: Editora Itatiaia, 1981. p. 146.

$3^{2}$ A transformação da mula-sem-cabeça que ocorre nas noites de quinta para sexta-feira é a punição de uma transgressão moral; em geral, o padre não é punido no folclore. 
de Spix e Martius é muito sugestiva do mesmo processo que estou trazendo aqui - as afinidades entre contos ou figuras de culturas diferentes. O que podemos constatar é um processo antropológico da primeira ordem: a procura de comparação.

No folclore português o complexo do lobisomem tem aspectos diferentes dos acima mencionados. Na realidade, encontramos que o lobisomem não está necessariamente ligado à forma zoológica de um lobo. Em vez disso, a pessoa é transformada em qualquer espécie de animal, normalmente um cão, um bode, um porco, um cavalo, um burro, ou qualquer outro animal de fazenda. ${ }^{35}$ De noite, o homem atormentado tira as suas roupas, pendura-as num pinheiro e rodopia nu na sujeira. Este ato de rodar afeta a transformação, o homem irá tornar-se no último animal que rebolou naquele lugar. Irá, então, correr muito rapidamente não procurando, necessariamente, animais ou humanos para comer, e regressará ao estado humano quando voltar a vestir as suas roupas. Lobisomens freqüentemente têm a pele amarela, uma condição que pode estar ligada ao consumo excessivo de álcool e à perda de sono. ${ }^{34}$

Assim, a pele é um elemento muito importante. O antropólogo português Francisco Vaz da Silva, num esforço para fazer sentido de uma referência obscura que lhe foi feita de passagem (acerca de escolher os filhos mais velhos de alguém para servir de padrinhos para os seus irmãos mais novos, começando com o sétimo), no seu trabalho de campo no norte de Portugal - argumenta que a metamorfose do lobisomem é

a conversão de uma forma animal interna numa forma animal externa... a qual ajusta-se com a noção difundida de que os lobisomens são "shifters de pele" [de James Frazer]. Isto supõe uma equivalência

A mula-sem-cabeça lança fogo pelo pescoço, dá coices relinchando e é muito semelhante ao lobisomem e à cumacanga. A história generalizou-se na Península Ibérica e tem também várias manifestações na América Espanhola. CÂMARA CASCUDO, Luís da. Op. cit. p. 191-195.

33 PEDROSO, C. Contribuições para uma mitologia popular portuguesa e outros escritos etnográficos. Org. J. Leal. Lisboa: Publicações Dom Quixote, 1988. p.187; VAZ DA SILVA, Francisco. Iberian born seventh born children, werewolves, and the dragon slayer: a case study in the comparative interpretation of symbolic praxis and fairytales. Folklore, v. 114, p. 345, 2003; LADURIE, E. Le Roy. Op. cit. p. 58.

$34 \mathrm{O}$ produto humano que resulta de um relacionamento sexual entre parentes, seja de compadrio, afinidade ou de sangue, poderia transformar em lobisomem (veja HARRIS, Mark. Life on the Amazon. Oxford: Oxford University Press, 2000). No livro O cacaulista, de Inglês de Souza (Op. cit., p. 139), uma senhora é acusada como feiticeira e lobisomem. $\mathrm{O}$ autor descreve sua aparència como magra, pálida, abatida e com pele amarela. Para suas relações sexuais com um padre, "a velha transformava em lobisomem, revestindo a figura de uma pata choca” (Op. cit., p. 139). Nota-se bem o termo "revestindo", que se liga com a transformação do boto em lobisomem de Portugal. 
básica entre a metamorfose como a fuga do duplo do animal do corpo como uma mudança de pele. ${ }^{35}$

A mudança de pele sugere uma ligação entre a transformação corporal e o xamanismo, seguindo a interpretação de xamanismo de Mircea Eliade, como uma viagem da alma. E será agora tempo de perguntar acerca de outros seres transformacionais nos quais Cavalcante se poderia tornar? ${ }^{36}$

E o que dizer de outros seres transformacionais, que Cavalcante supostamente poderia "virar"? Não temos detalhes, exceto a referência a "várias e defrentes figuras" e "semelhantes delírios", mas temos algumas sugestões recentes. Conforme bem se conhece, as localidades ribeirinhas da Amazônia contam histórias de botos que podem virar homem ou mulher, como quiserem. Encantados, espíritos invisíveis ("os bichos do fundo") com poderes especiais podem ir morar em animais, tais como a cobra, ou em locais, tais como um buraco fundo no rio ou no igarapé (geralmente indicado pela existência de redemoinhos, vórtices de correntes num curso d'água). A natureza dos encantados é deliberadamente ambígua, na maior parte dos casos eles fazem mal, mas seus poderes também são invocados para trazerem a cura a alguns tipos de humanos. O caboclo pajé é, por natureza, um ser transformacional, que tem o dom de nascença para curar ou para malinar. À noite ele pode deixar sua forma humana na rede e descer ao fundo das águas para visitar os encantados. Pode dominar os espíritos malevolentes em suas sessões de cura, ao identificar-se com eles.

Para dar um exemplo de um ser transformacional de origem ameríndia, irei referir-me ao boto-cor-de-rosa da Amazônia (Inia geoffrensis). $\mathrm{O}$ boto tem ciúme da natureza humana e é malicioso ao lidar com os humanos. Na parte da história mais conhecida, ele ouve, do rio, o barulho de uma festa de santo e quer fazer parte da diversão. Deixa a água, transforma-se num homem bem vestido, com um terno branco, chapéu e sapatos pretos, e procura a pista de dança. Ele começa a dançar e rapidamente atrai mulheres que não conseguem resistir aos seus encantos.

Finalmente ele desaparece na floresta com a que prefere e fazem amor. À medida que ela se recupera, ele escapa e retorna ao rio. A mulher irá ansiar por encontrar o homem de novo e, eventualmente, as pessoas perceberão que foi um boto que a seduziu e que ela precisará dos poderes especiais do pajé para se curar ${ }^{37}$. Os botos também atraem pessoas para os

35 VAZ DA SILVA, Francisco. Op. cit. p. 346, 2003.

36 É importante lembrar que a forma zoológica de lobo não tem nada a ver com o conceito de lobisomem dos séculos passados.

37 Cf. SLATER, C. The dance of the Dolphin. Chicago: Chicago University Press, 1994; LOUREIRO, J. de Paes. Cultura Amazônica: uma poética do imaginário. Belém: Cejup, 1995. 
seus reinos encantados no fundo do rio. Pelo menos em versões contemporâneas da lenda, as roupas que um boto usa são derivadas das mudanças corporais dos animais do rio, os sapatos são um par de arraias, e o chapéu uma tartaruga. Assim que o boto retorna à água, tudo se transforma ao anterior novamente. Em outras palavras, as roupas são parte importante da fuga do golfinho do rio para a terra, mas desta vez, na direção oposta à do lobisomem, ao colocá-las, em vez de as tirar, para assumir uma forma diferente.

Embora não exista lobo na Amazônia, a convivência com outros seres das águas e dos ares (pássaros) e o imaginário indígena subjacente a toda a realidade cultural da região permitiram a criação de outras figuras semelhantes à do lobisomem: a matinta pereira (pessoas que batem à porta e vêm pedir um pouco de tabaco e se transformam em pássaro), as pessoas que viram "porco" ou "cachorro".

Os conceitos e o papel cultural desse seres mágicos indubitavelmente sofreram mudanças desde o final do século XVIII. Embora não saibamos exatamente o que esses outros seres são, podemos, com uma boa dose de certeza, especular que eles derivam da imensa panóplia de criaturas encantadas de forma em constante mutação, que existem nos tempos contemporâneos. E sugeri acima minha impressão de que a razão pela qual as testemunhas se recusavam a dar-lhes um nome, bem como o escrivão a registrar tais nomes, era porque a Coroa Portuguesa estava tentando desesperadamente impor à Colônia padrões culturais europeus. A lembrança de que um lugar no sertão (interior) estaria cultivando abertamente crenças culturais híbridas, ou sustentando superstições dos índios, teria atraído o desprezo da metrópole.

Podemos relembrar a imagem do "fosso enorme" que separava as crenças e práticas religiosas populares do catolicismo oficial. No caso de Vila Franca no Baixo Amazonas, o único sinal da presença da Igreja era o padre, e, conforme já foi visto, é muito improvável que aquele padre tivesse tido interesse pelas questões teológicas mais refinadas; ademais, é preciso notar que ele contava com quase nenhuma estrutura institucional para dar apoio ao seu trabalho. Em um meio ambiente assim caótico e indisciplinado surgiram as convergências. Poderíamos dizer que havia uma "afinidade natural" na imaginação entre os mutáveis seres ameríndios e as tradições européias.

Embora ele não use a expressão "afinidade natural”, a implicação aparece claramente na reinterpretação feita por Carlo Ginzburg do famoso estudo clínico do homem-lobo feito por Sigmund Freud. Ginzburg indica que, faltando a Freud a percepção do folclore russo, ele deixou de compreender em sua plenitude o caso. Argumenta que Freud perdeu uma oportunidade excepcional de articular a conexão entre esferas filogenéticas e 
ontogenéticas de mitos tais como o do lobisomem. Para os nossos propósitos, o relevante é a insistência de Ginzburg de que, "de um ponto de vista histórico" (o destaque é dele), há uma conexão entre lobisomens e o sabbat que tem o benandanti como um elo intermediário: ambos podem ser considerados figuras num vasto stratum semi-apagado de crenças impregnadas de sobretons xamanísticos. Com essa base, não é de admirar que, nos mundos religiosos que foram elaborados na Amazônia Colonial, uma forma de pajelança cabocla, de caráter ameríndio e católico, e mitos a respeito de seres encantados se tornassem proeminentes.

\section{Pajelança e o terreno no meio}

Vou agora brevemente ligar o complexo do lobisomem com o xamanismo ou, como se fala na Amazônia, pajelança ou pajeria. De acordo com Carlo Ginzburg, o caráter transformativo do lobisomem faz parte de um espaço imaginativo que pode ser caracterizado como xamanismo. Não esqueçamos que ele está falando do antigo mundo, de uma Europa que não foi complementamente cristianizada. Isto é realmente um objetivo principal do trabalho dele; que existiam ao longo dos séculos focos de "sobrevivências" na Europa de práticas e crenças que predatam a introdução do cristianismo no século IV. Não sei se em Portugal do século XVIII existia tal foco de xamanismo tipo ibérico que foi transferido para a Terra de Santa Cruz. Mas podemos fazer duas observações. Havia uma tradição de curas, de poderes extraordinários, de transformações de pessoas em animais e também de viagens espirituais (veja-se Ginzburg ${ }^{38}$, pela busca das tradições xamanísticas na Europa). Podemos dizer também que, seguindo a linha da história das mentalidades, cada complexo de práticas e crenças carrega uma bagagem não articulada. Essa bagagem são os traços que foram reprimidos ou rejeitados no passado, porém continuam no presente como potências que podem ser realizadas. Mesmo que não tenha existido xamanismo propriamente em Portugal, havia os restos de um mundo subterrâneo ligado ao xamanismo como fenômeno histórico (não vou entrar no debate sobre o universalismo do xamanismo). O lobisomem fazia parte disso de forma explícita.

Estou sugerindo que os colonizadores, a maioria provinda da classe popular e do antigo campesinato do norte de Portugal, chegaram já ao Grão-Pará com as idéias xamanísticas da Europa. Como a instituição de compadrio com que se vincularam os índios e os primeiros colonizadores, a pajeria funcionou como um tipo de colar social. Atraiu todo tipo de pessoas

38 GINZBURG, Carlo. Ecstasies. Op. cit. 
e todas as classes, até governadores do Grão-Pará ${ }^{39}$. A sugestão é que o xamanismo dos mundos velho e novo ajudou o reconhecimento dos mundos imaginativos na América Portuguesa.

Fica claro nas fontes que vários tipos de xamanismo floresciam no século XVIII nas áreas urbanas e rurais, e tanto entre brancos quanto entre africanos e índios. Por quê? Uma resposta é que os diversos atores foram atraídos à cura e também à feitiçaria. E com a proliferação da participação, os rituais e práticas eram inovados no processo ${ }^{40}$. O teatro da pajelança e a feitiçaria foram terrenos férteis para a apropriação individual e a manipulação das novas formas de poder simbólico. Conforme Laura de Mello e Souza, essas atividades estavam ligadas à sobrevivência na Colônia: as pessoas precisavam de poderes mágicos para controlar as significados da vida.

Esse mundo emergido do xamanismo/pajelança então foi o contexto em que várias entidades, figuras e seres se ligam. Também volta o foco para o papel dos índios e sobretudo daqueles homens e mulheres que praticam formas de cura e feitiçaria. Estas posições eram as autoridades locais, as referências para negociar não só o mundo invisível e visível, mas também os mundos culturais, como é sempre observado nos estudos da pajelança na América do Sul. Igualmente aos padres e missionários, os novos pajés e curadores eram os mediadores de diversos interesses. $\mathrm{O}$ controle das forças novas e as formas simbólicas estavam nas mãos deles. Embora não possa desenvolver o argumento aqui, estou certo de que nas vilas e povoações do Grão-Pará foram os pajés que fizeram a grande parte do trabalho da imaginação. Há uma remota possibilidade de que Cavalcante, homem intelectual e político, formado em Coimbra, grandes ambições e interesse pela cultura dos índios, tenha sido um desses novos tipos de pajé e, por isso, adquirido o epíteto de "lobisomem".

\section{Conectando conceitos e fronteiras imaginativas}

Venho-me aproximando de uma linha de pensamento que sugere ter-se formado, por meio de um complexo de imagens relativas a humanos como seres transformacionais, surgindo dos "imaginários" das culturas em

39 Cf. AMARAL LAPA, R. (Org.). Op. cit.

4o Cf. Ibidem; SÃO JOSÉ QUEIRÓZ, D. Fr. João de. Viagem e visita do sertão em o Bispado do Gram Pará em 1762-3. Revista do Instituto Geográfico e Histórico Brasileiro, tomo 10, p. 43-107, 179-227, 328-375, 476-527, 1848; SOUZA, A. F. de. 1848. Noticias geographicas da capitania do Rio Negro no Grande rio Amazonas. Revista do Instituto Histórico e Geográfico Brasileiro, 10, 411-503. 
confronto (européia e ameríndia), uma ponte conceitual entre os vários atores. As experiências comuns de enfrentar as condições repressivas da vida numa parte marginal da Colônia, de estar desorientado seja pelo deslocamento (“desterrado"), seja pela escravidão virtual (no respeito dos ameríndios), e a falta de familiaridade com as técnicas e habilidades necessárias à sobrevivência nos mundos formados pelas áreas ribeirinhas e florestas (no respeito dos colonos e administradores) do Baixo Amazonas produziram uma série de reconciliações com bases locais entre os vários atores; mesmo que, no papel e aos olhos da Colônia, existissem lacunas imensas entre os tipos de pessoas vivendo num mesmo local. Aquele não era um meio ambiente em que alguém pudesse livrar-se das exigências do trabalho cotidiano, exceto os aleijados e doentes, não obstante todos os protestos dos oficiais pelo contrário. Compartilhar essas exigências, ainda que com certa desigualdade na sua distribuição, oferecia a possibilidade ou talvez até mesmo a necessidade de limites imaginativos para avaliar a situação. A conexão talvez já se realizasse coletivamente, mas não estava acontecendo de modo uniforme: pessoas em diferentes posições sociais na colônia teriam interpretado tais desdobramentos de forma variada, o que explica a natureza heterogênea das crenças folclóricas em evidência nos dias de hoje. O que quero ressaltar é que as idéias estavam expressas abertamente, liberadas de suas jaulas, podendo ser debatidas ou reprimidas.

No complexo da forma mutável, é possível então perceber um acoplamento entre as várias crenças e práticas (o substratum, para usar a frase arqueológica de Ginzburg) dos colonos ibéricos e os traços dos grupos ameríndios, forçados a se tornarem vassalos nas vilas. Essas pontes conceituais estavam unindo continentes e indivíduos com diferentes histórias. Começara uma dinâmica, da metade para o final do século XVIII, que reunia forças antagônicas num quadro de referência local, com o qual ambas precisavam desesperadamente se relacionar. Eis então o que Gruzinski chamou de "métissage dynamique" (mestiçagem dinâmica) ${ }^{41} \mathrm{com}$ pouca lógica ou estrutura, mas com movimento e conexão como princípio cultural. Para evocar a diferenciação feita por Ingold entre imaginação e inteligência, poderíamos dizer que a imaginação tentava solucionar problemas encontrados na experiência.

Embora algo novo estivesse emergindo, não era uma nova "cultura", ou um novo "imaginário". Era bem mais uma série de expressões singulares das relações negociadas e conflituosas entre os vários atores em um dado lugar, no caso a Vila Franca. Uma expressão na qual se encontravam

41 GRUZINSKI, Serge. O pensamento mestiço. Tradução R. Freire d’Aguiar. São Paulo: Companhia das Letras, 2000. 
tanto aspectos materiais como ideológicos, sendo que cada parte não estava necessariamente desenvolvida ou combinada de modo regular. Há certa ironia na observação de que os índios de melhor posição na aldeia começavam já a apresentar formas de vida mais européias, e os colonos pobres estavam aprendendo a viver e a trabalhar na região, para isso adotando uma mistura de conhecimento da técnica indígena e de métodos campesinos da Europa, enquanto os colonos mais ricos também estavam adaptando-se à Colônia, talvez usando escravos pela primeira vez. Em outras palavras, havia uma aprendizagem mútua de habilidades, crenças e visões de mundo deslocadas e transportadas de cada um, sem que houvesse de permeio um encontro realmente harmonioso entre esses padrões. Talvez sob a magia de um céu estrelado com a ajuda de uma garrafa de cachaça, ou nos momentos íntimos de prazer sexual, tenha havido empatias individuais.

Essas eram as condições da fronteira imaginativa da Colônia no crepúsculo do século XVIII no Baixo Amazonas. É de se perguntar por que referências tão escassas nesses documentos oficiais se referem a crenças folclóricas de figuras de transformação. A ênfase tanto do diretório como a das exigências políticas e econômicas mais amplas referiam-se fundamentalmente a uma mudança pessoal e coletiva de identidade: que o ameríndio se tornasse um vassalo de El Rey e o colono se adaptasse à Colônia, casasse com gente do local e se tornasse "brasileiro". Não estou dizendo que essas categorias sejam auto-evidentes, mas a força total da administração e de seus privilégios estava voltada nessas direções. Novas noções de $s i$ estavam sendo forjadas, ainda que não fossem aquelas que a Coroa pudesse ter desejado. Essas figuras imaginativas de mudança refletem as esferas materiais, oferecendo conceitos pragmáticos com os quais é possível pensar. Contudo, as fronteiras imaginativas ligando as diversas experiências no Baixo Amazonas não podiam ser arregimentadas tais quais religiões institucionalizadas como o Catolicismo. Faltavam-lhes raízes sociológicas firmes, sendo ao mesmo tempo rebeldes e criativas em sua conectividade do tipo jigsaw puzzle (quebra-cabeça de encaixes). A única forma institucional possível para essas crenças e práticas teria sido o pajé e seu conhecimento (e dom) de curar.

É significativo que o padre seja formalmente reconhecido como o ponto de origem da história do lobisomem. Ele estaria bem posicionado para conhecer o mundo religioso e imaginativo dos índios da aldeia e como explorá-lo. O padre sabia muito bem o que estava fazendo ao tornar públicas as acusações, ele teria conhecido bem as ligações entre os brancos e os ameríndios. É tentador especular que poderia ter sido o padre (e outros como ele) quem temerariamente sugeriu a ponte entre as idéias européias e ameríndias de seres transformacionais. Tendo ele casualmente 
feito a conexão, por nenhuma outra razão senão para desacreditar seu inimigo naquela localidade, "a coisa pegou", embora isto seja mover-se em direção ao reino da fantasia. Indica, contudo, a possibilidade de que as afinidades naturais discutidas anteriormente não ocorram naturalmente, mas em situações históricas bastante precisas, detonadas junto com as relações de poder que lhes provocaram a convergência. Eu deveria concluir afirmando que não estou pretendendo que essas pontes conceituais tenham conseguido êxito em unir as pessoas. Elas podem ter proporcionado a esperança de criar um contexto para que isso acontecesse, mas em sua essência a fronteira imaginativa, como um modo de ser, não encontrava apoio nem nas condições sociais, nem nas políticas. Em verdade, ela prometia mais do que podia realizar.

Ao focalizar o trabalho da imaginação na Amazônia Colonial do século XVIII, tentei oferecer uma nova perspectiva sobre esse período. Sendo a dizimação dos ameríndios e a imposição dos portugueses quase sempre descritas em termos apocalíticos ou maniqueístas, busquei mudar o foco da atenção para as pessoas que tomaram parte ativa nesse mundo colonial e suas lutas para criar um lugar para si mesmas, em que pudessem habitar de modo mais ou menos seguro. Apesar da violência e do abuso, resistência e morte, a partilha forçada desse mundo que os confrontava e a forma de imaginá-lo serviram à reconciliação dos diferentes grupos. Tradicionalmente, a antropologia não tem sido lá muito feliz em descrever esses compromissos e convergências frágeis e complexos, ou em encontrar um quadro de referência interpretativa para compreendê-los. Ao relacionar experiência com imaginação, conforme tentei fazer aqui, espero ter mostrado um modo de dar expressão a esse imenso mundo silencioso, cujos traços são as marcas das palavras trabalhosamente escritas à mão nas preciosas e frágeis páginas amareladas dos antigos documentos. 


\section{Datas de recebimento e aprovação dos artigos desta edição}

Cinema = Cavação:

Cendroswald Produções Cinematográficas

Carlos Augusto Calil

Recebido em 8 de junho de 2008

Aprovado em 6 de agosto de 2008

O lobisomem entre índios e brancos:

o trabalho da imaginação no Grão-Pará no final do século XVIII

Mark Harris

Recebido em 28 de abril de 2008

Aprovado em 29 de junho de 2008

A teoria da história de Caio Prado Jr.:

dialética e sentido

Jorge Grespan

Recebido em 1 de abril de 2008

Aprovado em 2 de maio de 2008

Caio Prado Jr. e a história agrária do Brasil e do México

Guillermo Palacios

Recebido em 27 de março de 2008

Aprovado em 12 de maio de 2008

Fronteiras da desordem:

saber e ofício nas experiências de Hélio Oiticica no Morro da Mangueira e de Carlos Nelson Ferreira dos Santos em Brás de Pina

Magaly Marques Pulhez

Recebido em 17 de abril de 2008

Aprovado em 24 de junho de 2008

"O linguajar multifário":

os estrangeiros e suas línguas na ficção de Mário de Andrade

Maria Caterina Pincherle

Recebido em 20 de março de 2007

Aprovado em 6 de agosto de 2008

Os nomes da língua:

configuração e desdobramentos do debate sobre a língua brasileira no século XIX

Olga Ferreira Coelho

Recebido em 26 de maio de 2007

Aprovado em 6 de agosto de 2008

Caetés:

nossa gente é sem herói

Erwin Torralbo Gimenez

Recebido em 5 de janeiro de 2007

Aprovado em 6 de agosto de 2008 